\title{
Linking Structural Empowerment to Employee-Driven Innovation: The Mediating Role of Psychological Empowerment
}

\author{
Chukwuemeka Echebiri *(D), Stein Amundsen and Marit Engen \\ Inland School of Business and Social Sciences, Inland Norway University of Applied Sciences, \\ Lillehammer Campus, 2626 Lillehammer, Norway; stein.amundsen@inn.no (S.A.); marit.engen@inn.no (M.E.) \\ * Correspondence: chukwuemeka.echebiri@inn.no
}

Received: 2 April 2020; Accepted: 25 June 2020; Published: 13 July 2020

\begin{abstract}
This paper aims to link structural empowerment to employee-driven innovation (EDI) with psychological empowerment as a mediation mechanism. Recently, there has been an increase in interest in utilizing all sources of knowledge in an organization to stimulate innovation among all employees. A clear understanding of some of the mechanisms used to achieve this is needed. The paper applies a quantitative approach based on two studies. Study 1 involved a total of 228 employees in a public sector organization, while study 2 involved 60 employees from a private sector organization. We employed structural equation modeling to test the hypothesized relationships among the variables. It was determined that both structural empowerment and psychological empowerment have a direct positive association with EDI. Second, the relationship between structural empowerment and EDI was partially mediated by psychological empowerment. EDI can only happen in an organization if employers and managers empower the ordinary employees to not only generate creative ideas but also to participate in its development and implementation.
\end{abstract}

Keywords: employee-driven innovation; structural empowerment; psychological empowerment

\section{Introduction}

Several studies have acknowledged the importance of innovation in modern organizations (Hartley 2005; Snyder et al. 2016; Pieterse et al. 2010; Osborne and Brown 2011). The modern economy is characterized by globalization, dynamism and more knowledgeable employees, as customers and citizens are continually expecting better services. Therefore, both public and private organizations continually strive to renew themselves, and service innovation is viewed as one of the main channels for improvement (Helkkula et al. 2018; Carlborg et al. 2014; Durst et al. 2015; Witell et al. 2016). Osborne and Brown (2011) argue that the dominance and influence of innovation on public policy and innovation in public services would remain essential to meet the economic and social challenges of today.

To enhance innovative capabilities, organizations should exploit all sources of knowledge (Alasoini 2013) instead of restricting innovation to only a few within the organization (Høyrup 2012; Kesting and Ulhøi 2010). As such, new models of innovation have suggested more active and diverse roles for all employees within the organization. One of these models is expressed through the conceptual framework of employee-driven innovation (EDI), which embraces innovation activities that are initiated and driven by ordinary employees (Renkema 2018; Smith et al. 2012; Båckstrom and Lindberg 2018). To drive innovation implies that employees participate in both the generation of creative ideas and their implementation (Smith et al. 2012; Bäckström and Lindberg 2019). Kesting and Ulhøi (2010) argue that "for ordinary employees, to drive innovations largely means participating in those organizational 
decision-making procedures by which innovations are triggered and determined" (p. 68). According to Aaltonen and Hytti (2014), contextual factors such as organizational structures could act as a barrier to innovation. In a more recent study, Renkema et al. (2018) suggest that organizations cannot utilize the innovation potential of ordinary employees if they fail to empower those employees. By implication, it means removing the contextual barriers that inhibit the participation of ordinary employees in innovation activities. This indicates that empowerment could play an important role in facilitating EDI. Yet, the role of empowerment in EDI has not been previously investigated in the context of EDI. In general, studies show that even though empowering initiatives are enabling, sometimes they could be a burden as well (Cheong et al. 2016).

Empowerment is a concept that describes working arrangements in which the empowered is engaged at an emotional level (Conger and Kanungo 1988). Kanter (1977) argues that empowerment results from decentralization, a flattening of the hierarchy and increased employee participation. Amundsen (2014) suggests that the involvement of employees and power-sharing with employees are at the core of empowerment. This includes giving employees more freedom and autonomy in the workplace (Amundsen 2014; Amundsen and Martinsen 2015). Empowerment enables employees to learn to use their initiative and act more creatively (Laschinger et al. 2004; Humborstad 2012). In this context, Conrad (2017) suggests that through empowerment, organizations engage and enable their employees to take responsibility. Thorlakson and Murray (1996), cited by Laschinger et al. (2004) described empowerment as a tool to encourage employees to independently reflect about their work instead of continuously engaging in the usual routine.

According to Kanter (1988), employees are unlikely to initiate processes that deviate from established organizational routines and practices if they are not empowered. In this paper, we draw on the argument that employees need to be empowered by organizational structures to participate in the organizational decision-making procedures by which innovations are triggered and determined (Kesting and Ulhøi 2010). However, structural empowerment may not be enough for EDI to occur. Studies have shown that when employees are psychologically empowered, such employees are more likely to believe they are autonomous, more impactful, creative and less likely to be constrained by technical or rule-bound aspects of work (Spreitzer 1995; Spreitzer and Doneson 2005). In a recent study, Lempiala and Yli-Kauhaluoma (2019) highlighted how teams with similar structural support and resources could differently perceive their ability to engage in EDI. Thus suggesting that empowering structures may not be enough for EDI but how employees experience and interpret these matter.

Consequently, this paper aims to develop and test a model that focuses on how the two main approaches of empowerment (structural and psychological empowerment) associate with EDI. Accordingly, this paper makes the following contributions: First, we contribute to the EDI body of knowledge by developing and empirically testing a model that links structural and psychological empowerment to EDI. We show that a work environment that is considered to be structurally empowering will positively influence EDI. Secondly, we reaffirm the positive relationship between structural empowerment and psychological empowerment. Lastly, we demonstrate that the association between structural empowerment and EDI is partially mediated by psychological empowerment.

We organize the rest of this paper as follows: Next, we discuss the theoretical perspectives and formulate the study's hypotheses, followed by the research methodology. After that, we present our analyses, conclusion and limitations of the study.

\section{Theory and Hypotheses}

\subsection{Employee-Driven Innovation}

EDI belongs to an umbrella concept, usually referred to as workplace innovation. This is because employees' contribution and EDI are based upon how their innovation activities are embedded within their work practice. The premise for EDI is that employee participation is seen as a means of increasing 
productivity, achieving more influence on the decision-making process and subduing conflicts and democratization of society (Aasen et al. 2012; Bäckström and Bengtsson 2019).

EDI is a concept that describes innovation whereby a new idea, product or process is initiated and implemented by a single employee or by the joint effort of two or more employees (Kesting and Ulhøi 2010; Høyrup 2010). EDI emphasizes innovation as a process wherein ordinary employees are seen as the primary sources and drivers of innovation (Saari et al. 2015; Lempiala and Yli-Kauhaluoma 2019; Holmquist and Johansson 2019; Kurz et al. 2018). Because these employees are not required to be involved in innovation, EDI is therefore described as an extra role behavior (Renkema 2018; Buhl 2018). The argument for employee participation is based on the idea that these employees regularly face challenges through their work practices and are ideally positioned as a source of innovation (Wihlman et al. 2014; Båckstrom and Lindberg 2018). In addition, the employees' knowledge of their work practices puts them in a position to gain a context-dependent understanding that their managers might lack (Kesting and Ulhøi 2010). Despite the fact that employees are acknowledged as essential sources for innovation, their creative potential is often underutilized (Saari et al. 2015).

Following Saari et al. (2015), participatory decision making and power-sharing are some of the factors that facilitate EDI. In a recent study, Voxted (2018) identified management support as one of the key factors that facilitate EDI. These factors determine the extent that employees can develop and use their competencies as well as their creative potentials (Totterdill and Exton 2014), and are mostly dependent on the kind of workplace where employees perform their jobs. Innovation (including EDI) depends on an employee's network of relationships within the organization, "because it is these relationships that provide the requisite inspiration, information, resources, and support that help innovators develop, promote, and realize their new ideas" (Wang et al. 2015, p. 1).

\subsection{Employee Empowerment}

Empowerment can be traced back to studies on employee involvement and participation that were carried out over six decades ago (Maynard et al. 2012). It implies a range of management practices (e.g., sharing authority, resources, information) that directly affects work outcomes (e.g., quality, productivity, customer satisfaction). It also indirectly affects them by influencing employee cognitions (e.g., self-efficacy, motivation) (Fernandez and Moldogaziev 2013; Spreitzer 1995; Vecchio et al. 2010). Amundsen and Martinsen (2015) argue that to empower is concerned more with the transfer of influence to another than with influencing another. They further stated that work designs that flow from empowerment approaches are characterized by autonomy, self-leadership, the delegation of responsibility and decision making authority. In this regard, Wong Humborstad and Perry (2011) suggest that empowerment is a form of employee involvement initiative, which explains the degree to which employees are allowed to make decisions without recourse to their superiors.

Empowerment literature indicates that two dominant views of empowerment have gradually emerged over the years (Amundsen 2019; Maynard et al. 2012; Rhee et al. 2017). These are the social-structural and the psychological approach. Conceptually, social-structural empowerment is made of both structural and social empowerment (Amundsen 2014). The structural approach is linked to structural aspects, such as information, resources, decentralization, knowledge and authority (Maynard et al. 2012). In contrast, social empowerment is linked to relational aspects such as between leaders and their subordinates or among employees themselves (Amundsen 2014). The social perspective is also called the relational perspective in the literature. However, both the structural and social aspects are aimed at fostering psychological empowerment and are based on employees' perceptions of their work role (Amundsen and Martinsen 2015; Baird et al. 2018). This paper focuses on the structural part of the social-structural approach of empowerment.

\subsection{Structural Empowerment}

Structural empowerment, sometimes referred to as managerial empowerment, focuses on how individuals with power and authority in an organization (managers) share it with those that lack 
it (employees) (Conger and Kanungo 1988; Fernandez and Moldogaziev 2013). It derives from organizational theories with the main emphasis on the delegation of power and authority (Knol and Van Linge 2009). At the core of structural empowerment is the transition of authority and responsibility from upper management to employees (Maynard et al. 2012). It is described as a fundamental determinant that influences behavior, whereby employees with sufficient empowerment can fulfil the tasks (Knol and Van Linge 2009). Structural empowerment implies that lower-level employees in an organization are enabled to take appropriate action through a set of structures, practices and policies within the organization that result from a flattening of the hierarchy (Seibert et al. 2011). Previous studies have found that structural empowerment leads to innovative behavior (Knol and Van Linge 2009; Hebenstreit 2012; Dan et al. 2018).

Drawing from Kanter's theory of structural empowerment, Kanter identified four work empowerment structures: information, resources, support and opportunity (Kanter 1977, 1979). Research shows that having access to information, receiving support, having access to resources necessary to do one's job and having the opportunity to learn and grow are considered as empowering structures. When employees are structurally empowered, the manifestation in the organization is reflected by access to these structures facilitated by formal job characteristics (Laschinger et al. 2001). Kesting and Ulhøi (2010) suggested that a lack of time, resources and information would considerably hamper employees' idea generation.

According to Kesting and Ulhøi (2010), in an ideal type of organizational structure that promotes EDI, employees can propose changes while management can delegate the decision authority to employees. The implication is that employees who are not required to take on the task of innovation now begin to do so through organizational designs. That is, the organization's ability to offer access to information, resources, support and opportunity in the work environment has a major impact on innovation (O'Brien 2010). In their study, Hansen et al. (2017) noted that de-emphasizing an organisational structure was among the most critical factors for successful innovation. Based on the above discussion, we put forward the following hypothesis:

\section{H1: There is a positive relationship between structural empowerment and EDI.}

\subsection{Psychological Empowerment}

Psychological empowerment has its foundation in social psychological theory based on personal development. Conger and Kanungo (1988) defined psychological empowerment as a motivational construct. Their view of empowerment shifted the perception of empowerment to the individual. Thomas and Velthouse (1990) elaborated Conger and Kanungo's work further, and linked empowerment to increased intrinsic task motivation. The focus here is on employees' perceptions or cognitive states regarding empowerment, thus regarded as individual perspective on empowerment (Maynard et al. 2012; Menon 2001).

Psychological empowerment manifests in four cognitions reflecting an individual's orientation to his or her work role: meaning, competence, self-determination and impact (Spreitzer et al. 1999; Thomas and Velthouse 1990). These four dimensions combine into the overall construct of psychological empowerment (Spreitzer 1995; Spreitzer and Doneson 2005). Meaning reflects on how one's feels that one's work is personally important (Knol and Van Linge 2009). Competence refers to the belief in one's ability to successfully perform one's job (Laschinger et al. 2001). Autonomy (self-determination) indicates the perceptions of how free one is to choose how to initiate and carry out tasks (Laschinger et al. 2004). Impact concerns the extent to which one perceives one's behaviors as making a difference in work outcomes (Spreitzer 1995).

As investigated and noted in other studies, psychological empowerment can be viewed as a mechanism that mediates the relationship between structural empowerment and different work outcomes (Knol and Van Linge 2009; Laschinger et al. 2001; O’Brien 2010; Amundsen and Martinsen 2015; Wagner et al. 2010; Seibert et al. 2011). Research has consequently indicated that the two major 
approaches of empowerment are related. Psychological empowerment is a reaction to structural empowerment (Amundsen and Martinsen 2015; Corsun and Enz 1999; Camilla and Krishna 2015), as it underscores employees' reactions to structural empowerment conditions (Knol and Van Linge 2009; Laschinger et al. 2004; O’Brien 2010). According to Laschinger et al. (2004), "by increasing access to work empowerment structures, employee experience feeling of personal empowerment ... " (p. 268).

We postulate as follows:

H2: There is a positive relationship between structural empowerment and psychological empowerment.

Previous studies indicate that empowerment and allowing autonomy are crucial as they stimulate idea generation in employees (Avolio et al. 1991; Russell and Stone 2002; Wagner et al. 2010), and are therefore conducive to the generation of innovations (Laschinger et al. 2001). It enables employees to respond more quickly to customer service requests, act to rectify complaints and be more engaged in service encounters (Conrad 2017; Laschinger et al. 2004). Empowered employees are likely to feel more self-efficacious (Amabile 1988; Spreitzer 1995), and have more significant opportunities for self-direction (Vecchio et al. 2010). Also, research suggests that empowerment initiatives lead to enhanced employee performance, well-being and positive attitudes (Maynard et al. 2012), which may also have a positive impact on their innovation attempts. Above all, previous studies show that empowered employees are more innovative (Fernandez and Pitts 2011; Fernandez and Moldogaziev 2013).

EDI is a complex process made up of different activities, which includes emergence and search of ideas, idea generation and development as well as the implementation of ideas (Echebiri et al. forthcoming). For example, idea generation itself is a creative process that requires employees' internal desire for creativity, learning and development (Alasoini 2013). Previous studies indicate that empowerment and allowing autonomy is indeed conducive to idea generation in employees. That is to say that employee participation stimulates idea generation and is, therefore, helpful to the generation of innovations (Kesting et al. 2015).

As previously argued, ordinary employees are not expected to take on the role of being innovators. Instead, they are expected to undertake various supportive functions and implement management decisions (Kesting and Ulhøi 2010). However, empowerment encourages employees to think for themselves and ultimately move beyond doing blindly what they are told to do (Laschinger et al. 2004). By being empowered, employees may learn to take the initiative and creatively respond to the challenges of the job. Hence the following hypotheses:

H3: There is a positive association between psychological empowerment and EDI.

Since previous studies have suggested that psychological empowerment is a reaction to structural empowerment, we also expect psychological empowerment to act as a mediation mechanism between structural empowerment and EDI. The mediation role of psychological empowerment between work environment structures and work outcomes has been supported by previous studies (e.g., Camilla and Krishna 2015; Rhee et al. 2017). However, owing to the nature of social reality, we expect the mediation to be partial rather than complete, which implies that structural empowerment would manifest direct associations with EDI but have an indirect effect via psychological empowerment. This leads to the following (see Figure 1):

H4: Psychological empowerment will partially mediate the relationship between structural empowerment and EDI. 


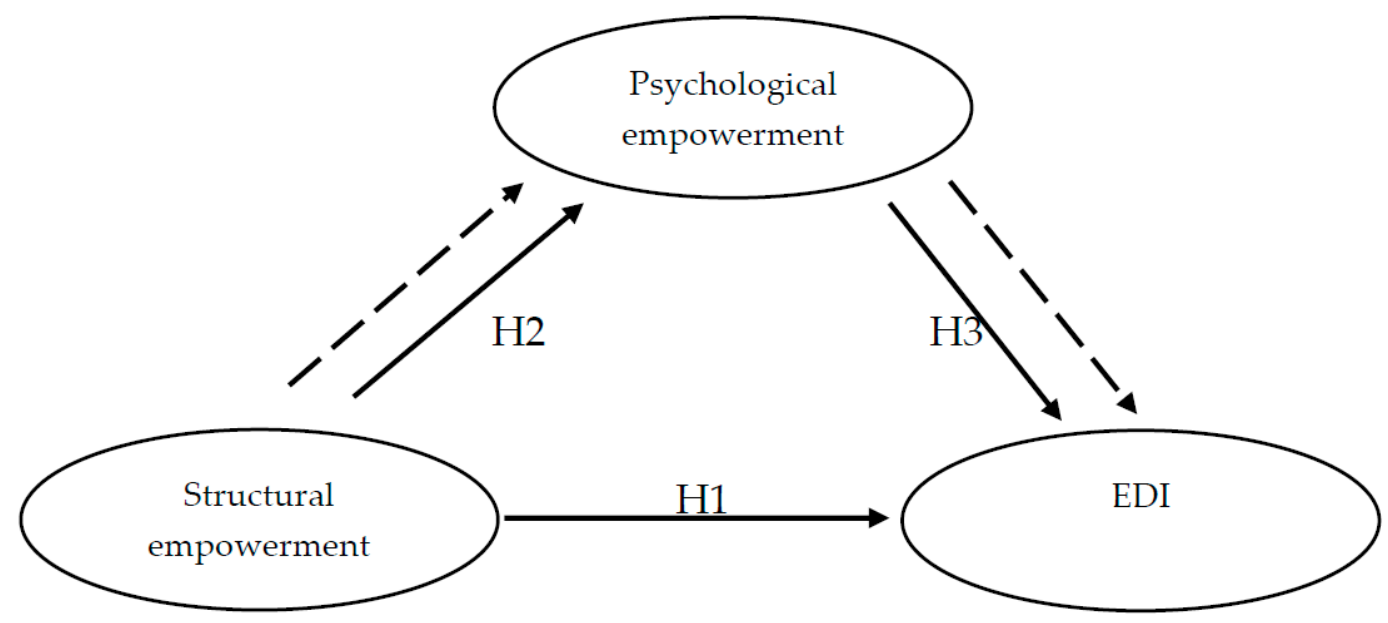

Figure 1. Hypothesized model. Notes: Direct parts are represented with straight arrows. The mediation part is represented with the dashed arrows.

\section{Study 1: Methodology}

\subsection{Data Collection and Sample Attributes}

We collected data from the Norwegian Labour and Welfare Administration (NAV). Based on an onging research collaboration between our research group and the organization, we relied on the convenience sampling method. We designed our survey instrument using Checkbox. Checkbox is a professional tool for conducting online surveys (Checkbox 2018). A link to the survey with an explanation was sent to our contact person in the organization, who then distributed it among other employees. A total of 461 employees received the survey and 228 employees completed it, representing a response rate of $49 \%$. Of these, 68 respondents (30\%) were males, while $160(70 \%)$ were females. There were 186 respondents $(82 \%)$ who reported that they were subordinates, whereas $42(18 \%)$ had leadership responsibilities. Among the respondents, 160 (70\%) had contact with users, and $68(30 \%)$ had no contact with users.

\subsection{Common Method Bias (CMB)}

To deal with common method variance, which is usually associated with studies that rely on self-reported data collected at the same point in time (Podsakoff et al. 2003; Chang et al. 2010), we implemented two ex-ante remedies at the research design stage (Conway and Lance 2010). First, our survey was designed to be anonymous. It has been suggested that protecting the anonymity of the respondents minimizes the evaluation apprehension and can reduce method bias. Second, we counterbalanced the order of the measurement of our dependent and independent variables, as suggested in previous studies (Podsakoff et al. 2003). According to Chang et al. (2010), counterbalancing the order of items in relation to different scales and constructs makes CMV less likely.

\subsection{Research Instruments}

All items used for this study were scored using a seven-point Likert scale rated from 1 (strongly disagree) to 7 (strongly disagree).

Employee-Driven Innovation (EDI). We measured EDI with a 13 items scale developed by Echebiri, Engen, and Amundsen (in press). The scale is comprised of the following three sub-dimensions: Emergence and search for ideas (four items), idea generation (three items), and idea development and implementation (six items). The Cronbach alpha were $0.89,0.88$ and 0.92 , respectively. Sample items include emergence and search for ideas (I recognize when there is an opportunity for improvement with a new practice), idea generation (I come up with creative ideas that might improve daily work), and idea development and implementation (When a developed idea is put into practice, it becomes part 
of the routine). The fit indexes for three first-order factors (three dimensions) plus one second-order factor fell within an acceptable range $\left[\chi^{2}(62)=191.25, p<0.001 ; \mathrm{CFI}=0.95\right.$; TLI $=0.94$; $\mathrm{RMSEA}=0.09$; SRMR $=0.04$ ]. The overall scale reliability of EDI was 0.78. All indicators exhibited significant relationships $(p<0.001)$ with their intended latent variable (range $=0.71$ to 0.89 ).

Structural empowerment. Structural empowerment was assessed with an 11-item scale adapted from the conditions of work effectiveness questionnaire (Havaei and Dahinten 2017). The scale is originally made up of four sub-dimensions that is opportunity, information, support and resources, with each having three items. Because discriminant validity was not achieved for resources, the item that had the lowest $r$-squared value for the construct was dropped. Sample items include; opportunity (I have the chance to gain new skills and knowledge on the job), information (I am informed about the policies and procedures to do my job well), support (I get specific information about things I do well) and resources (I have the resources I need for my job). The fit indexes for four first-order factors plus one second-order factor fell within an acceptable range $\left[\chi^{2}(38)=149.54, p<0.001 ; \mathrm{CFI}=0.93\right.$; $\mathrm{TLI}=0.90 ; \mathrm{RMSEA}=0.10 ; \mathrm{SRMR}=0.65]$. The overall scale reliability for structural empowerment was 0.78. All indicators exhibited significant relationships $(p<0.001)$ with their intended latent variable (range $=0.68$ to 0.88 ).

Psychological empowerment. We assessed psychological empowerment with the Spreitzer (1995) 12-item scale. The scales comprises of four sub-dimensions: meaning, competence, impact and autonomy with each having three items $(\alpha=0.87,0.87,0.90$ and 0.94 , respectively). Sample items included: meaning (The work I do is very important to me), competence (I am confident about my ability to do my job), autonomy (I have autonomy in determining how I do my job) and impact (My impact on what happens in my department is large). The fit indexes for the four correlated first-order factors model fell within an acceptable range $\left[\chi^{2}(50)=118.03, p<0.001\right.$; CFI $=0.97$; TLI $=0.96$; RMSEA $=0.07 ;$ SRMR $=0.06]$. The overall scale reliability for psychological empowerment was 0.78. All indicators exhibited significant relationships $(p<0.001)$ with their intended latent variable (range $=0.80$ to 0.95 ).

Control variables. Previous studies show that control variables can influence the result (Bos-Nehles and Veenendaal 2017). We controlled for three semi-demographic characteristics including gender, education and contact with clients. Table 1 shows that education is only significant to another control variable (user contact), which means that no control variables impacted on the substantive variables. Therefore, control variables were excluded from further analysis.

Table 1. Mean, Standard deviation and scale correlations.

\begin{tabular}{cccccccc}
\hline Mean & SD & $\mathbf{1}$ & $\mathbf{2}$ & $\mathbf{3}$ & $\mathbf{4}$ & $\mathbf{5}$ & $\mathbf{6}$ \\
\hline Gender & 1.70 & 0.46 & & & & & \\
Education & 2.94 & 0.68 & -0.08 & & & & \\
User contact & 1.30 & 0.46 & -0.16 & $0.24^{* * *}$ & & & \\
Structural empowerment & 5.8 & 0.84 & -0.10 & 0.33 & 0.02 & & \\
Psychological empowerment & 6.2 & 0.59 & -0.04 & 0.17 & 0.07 & $0.74^{* * *}$ & \\
EDI & 5.5 & 0.78 & -0.18 & 0.14 & -0.05 & $0.66^{* * *}$ & $0.64^{* * *}$ \\
\hline & Note: & $* 0.01^{* * * *}=p<0.001$. & & &
\end{tabular}

\subsection{Data Analyses}

To test the hypotheses, we employed structural equation modeling (SEM) using Stata version 15.1 (StataCorp. 2017) with maximum likelihood (ML) estimation. Seven observations with missing values were automatically excluded in the analysis. As recommended by Mehmet and Jakobsen (2017), we reported multiple goodness-of-fit indices for CFA, as the chi-square test is known to be sensitive to the sample size. These include: (a) test statistics, degrees of freedom and significance level for the chi-square test; (b) RMSEA (root mean square error of approximation) and $90 \%$ CIs, with values of 0.05 indicating a close fit (Acock 2013) and values $<0.10$ indicating an acceptable fit (Mehmet and Jakobsen 2017); (c) SRMR (standardized root mean square residual), with values $\leq 0.1$ indicating a good 
fit (Mehmet and Jakobsen 2017); and (d) CFI (comparative fit index) and TLI (Tucker-Lewis index), with values $>0.90$ generally indicating an acceptable fit (Acock 2013).

The analyses were done in two major parts. First, the measurement model was tested, and this was followed by examining the hypotheses with a structural model. Descriptive statistics, a bivariate correlation of the research constructs and control variables are reported in Table 1.

\subsection{Test of the Measurement Model}

First, confirmatory factor analyses (CFA) was used to assess the first-order measurement model. We verified the reliability, item loadings, factor reliability, convergent validity and discriminant validity of the scales used. The model included 36 items capturing 11 first-order correlated latent constructs. The measurement model shows an acceptable fit $\left[\chi^{2}(539)=1034.70, p<0.001\right.$; CFI $=0.93$; TLI $=0.92$; RMSEA $=0.06 ;$ SRMR $=0.05]$. In addition, the average variance extracted (AVE) of all latent construct confirmed the reliability and construct validity (Acock 2013). AVE for all constructs was over 0.50 (0.54-0.83), showing the convergent validity of the constructs. Also, the measurement model exhibited discriminant validity because the AVE for all constructs was larger than the squared correlation between constructs (Acock 2013; Mehmet and Jakobsen 2017). Raykov's factor reliability coefficient for all of the 11 correlated constructs was above the recommended minimum of 0.70 (0.74-0.94) (Mehmet and Jakobsen 2017). Standardized factor loadings of the measurement items, scale reliability indicators and average variance extracted (AVE) are reported in Table 2.

Since the three constructs under study (structural empowerment, psychological empowerment, and EDI) were reflective variables, we added and tested a second-order reflective measurement model in which items loaded on the first-order factors and were used as indicators for the second-order factor. The results were satisfactory and the overall goodness of fit were all above the recommended minimum $\left[\chi^{2}(580)=1437.25, p<0.001 ; \mathrm{CFI}=0.90 ; \mathrm{TLI}=0.90 ; \mathrm{RMSEA}=0.07 ; \mathrm{SRMR}=0.09\right]$. In addition, there was no problem with both discriminant and convergent validity. Having established a good measurement model at both first-order and second-order levels, we proceeded with the structural model using this measurement model.

\subsection{Test of the Structural Model}

Our hypotheses were tested based on bivariate variable correlation in Table 1. Hypothesis 1, which postulated that structural empowerment has a positive relationship with EDI, was supported in a statistically significant way $(\beta=0.66, p<0.001)$. Hypothesis 2 postulated that there is a relationship between structural empowerment and psychological empowerment. This hypothesis was supported $(\beta=0.74, p<0.001)$. Hypotheses 3 , which predicted that there is a positive relationship between psychological empowerment and EDI, was also confirmed $(\beta=0.64, p<0.001)$. With significant results in all the three parts tested in Hypotheses 1, 2 and 3, preliminary support for $\mathrm{H} 4$ was demonstrated. We tested for mediation based on our structural model. To test our structural model, we set the mat size to 5000. Mat size is a mechanism that controls the internal size of matrices that Stata uses. (StataCorp. 2017). Structural modeling results suggested that the hypothesized model fit the data well $(\chi 2[614]=1455.21, p<0.001 ; \mathrm{CFI}=0.90 ; \mathrm{TLI}=0.90 ; \mathrm{RMSEA}=0.07 ; \mathrm{SRMR}=0.09)$.

However, we ran mediation analyses based on the hypothesized model to determine if mediation was partial or full and proportion of the effect. We performed the mediation test using a program developed for Stata with Monte Carlo replications. Monte Carlo replication is considered to be a good alternative to bootstrapping, as it takes less time and still acceptable (Jose 2013; Mehmet and Jakobsen 2017). The number of Monte Carlo replications was set to 5000. The analyses showed that mediation was partial. The average indirect effect of structural empowerment on EDI was estimated to be $0.54, \mathrm{SE}=0.10, p<0.001,95 \% \mathrm{CI}[0.34,0.75]$. The ratio of indirect effect to total effect was 0.65 ; this meant about $65 \%$ of the effect of structural empowerment on EDI was mediated by psychological empowerment. 
Table 2. Items and Confirmatory Factor Analysis results.

\begin{tabular}{|c|c|c|c|}
\hline Assessment of Measurement Items & $\begin{array}{c}\text { Standardized Factor } \\
\text { Loadings }\end{array}$ & $\begin{array}{c}\text { Raykov's Factor } \\
\text { Reliability Coefficient }\end{array}$ & AVE \\
\hline \multicolumn{4}{|l|}{ Employee-Driven Innovation } \\
\hline Emergence and search for ideas & & 0.87 & 0.64 \\
\hline I recognize when there is an opportunity for improvement with a practice & 0.84 & & \\
\hline I always identify when there is an opportunity for improvement with a practice & 0.83 & & \\
\hline I am able to search for solutions to identified problems & 0.80 & & \\
\hline I can identify when there are problems with a daily routine/practice & 0.72 & & \\
\hline Idea generation & & 0.88 & 0.71 \\
\hline I often come up with creative solutions to problems at work & 0.80 & & \\
\hline I am good at generating original solutions for problems & 0.84 & & \\
\hline Idea development $\mathcal{E}$ Implementation & & 0.92 & 0.66 \\
\hline When a developed idea is put into practice, it becomes part of the routine & 0.83 & & \\
\hline We are good at implementing new ideas & 0.88 & & \\
\hline We systematically implement innovative ideas into work practices & 0.79 & & \\
\hline Implemented ideas become part of the routine & 0.85 & & \\
\hline There is a process for developing ideas in the department/unit & 0.80 & & \\
\hline We develop suitable plans and schedules for the implementation of new idea & 0.71 & & \\
\hline Opportunity & & 0.87 & 0.71 \\
\hline My work provides me with challenges to grow at work & 0.86 & & \\
\hline I have the chance to gain new skills and knowledge on the job & 0.78 & & \\
\hline My job provides me with the possibility for growth & 0.88 & & \\
\hline Information & & 0.79 & 0.54 \\
\hline I am informed about the goals and strategy needed to do my job well & 0.77 & & \\
\hline I am informed about the policies and procedures needed to do my job well & 0.85 & & \\
\hline I have access to the necessary information to do my job well & 0.66 & & \\
\hline Support & & 0.85 & 0.63 \\
\hline I get specific information about things I do well & 0.88 & & \\
\hline I receive helpful hints or problem solving advice & 0.87 & & \\
\hline I get comments about things that I could improve & 0.62 & & \\
\hline Resources & & 0.74 & 0.58 \\
\hline I have available materials to accomplish job requirements & 0.68 & & \\
\hline I have the resources I need for my job & 0.84 & & \\
\hline
\end{tabular}


Table 2. Cont

\begin{tabular}{|c|c|c|c|}
\hline Assessment of Measurement Items & $\begin{array}{c}\text { Standardized Factor } \\
\text { Loadings }\end{array}$ & $\begin{array}{c}\text { Raykov's Factor } \\
\text { Reliability Coefficient }\end{array}$ & AVE \\
\hline \multicolumn{4}{|l|}{ Psychological Empowerment } \\
\hline Meaning & & 0.87 & 0.70 \\
\hline My job activities are personally meaningful to me & 0.82 & & \\
\hline The work I do is meaningful to me & 0.84 & & \\
\hline Competence & & 0.85 & 0.66 \\
\hline I am confident about my ability to do my job & 0.81 & & \\
\hline I have the skills necessary for my job & 0.82 & & \\
\hline Autonomy & & 0.90 & 0.76 \\
\hline I have significant autonomy in determining how I do my job & 0.89 & & \\
\hline I can decide on my own how to go about doing my work & 0.85 & & \\
\hline I have considerable opportunity for independence and freedom in how I do my job & 0.86 & & \\
\hline Impact & & 0.94 & 0.83 \\
\hline My impact on what happens in my organization/department is large & 0.93 & & \\
\hline I have a great deal of control over what happens in my department & 0.85 & & \\
\hline I have significant influence over what happens in my department & 0.95 & & \\
\hline
\end{tabular}

$\left[\chi^{2}(539)=1034.70, p<0.001 ; \mathrm{CFI}=0.93 ; \mathrm{TLI}=0.92 ; \mathrm{RMSEA}=0.06\right.$; $\left.\mathrm{SRMR}=0.05\right]$. 


\section{Study 2: Methodology}

The purpose of Study 2 was to replicate the study in another organization and sector with different situational factors. Since study 1 was done in a public sector organization, we carried out study 2 in a private sector organization. The main elements of the research design were the same. The data collection procedure, the steps adopted to check common method bias were same as for study 1 . The measurement instruments were also the same.

\subsection{Data Collection and Sample Attributes}

A total of 202 employees of the Nordic Choice hotel received the survey. After two reminders, 60 completed the survey, representing a response rate of $30 \%$. Of these, 27 respondents $(45 \%)$ were males, while $33(55 \%)$ were females. There were 23 respondents $(38 \%)$ who reported that they were subordinates, whereas $37(62 \%)$ had leadership responsibilities. Among the respondents, $39(65 \%)$ had contact with guests, and 21 (35\%) had no contact with users.

\subsection{Control Variables}

Similar to for study 1, we controlled for three semi-demographic characteristics including gender, education and contact with clients. However, the correlation analysis show that the control variables had no significant relationships with the substantive variables and were therefore excluded from further analysis.

\subsection{Data Analyses}

We decided to perform SEM using Partial Least Squares Structural Equation Modeling (PLS-SEM). PLS-SEM is recommended by scholars (e.g., Venturini and Mehmet 2019; Wong 2019) when the sample size is small, as was the case with our data. We used a package developed by Venturini and Mehmet (2019) for Stata.

We began with the descriptive statistics and correlation analyses of the research construct. Table 3 displays the bivariate correlations between the main constructs and control variables and gives preliminary support to hypotheses 1-3.

Table 3. Mean, Standard deviation and scale correlations.

\begin{tabular}{cccccccc}
\hline Mean & SD & $\mathbf{1}$ & $\mathbf{2}$ & $\mathbf{3}$ & $\mathbf{4}$ & $\mathbf{5}$ & $\mathbf{6}$ \\
\hline Gender & 1.55 & 0.50 & & & & & \\
Education & 2.97 & 0.72 & -0.23 & & & & \\
User contact & 1.35 & 0.48 & -0.25 & 0.18 & & & \\
Structural empowerment & 5.8 & 0.84 & 0.11 & -0.04 & 0.12 & & \\
Psychological empowerment & 6.2 & 0.59 & -0.06 & -0.02 & 0.10 & $0.67^{* * *}$ & \\
EDI & 5.5 & 0.78 & 0.03 & -0.81 & -0.08 & $0.60^{* * *}$ & $0.59^{* * *}$ \\
\hline \multicolumn{7}{c}{ Note: } \\
*** $=p<0.001$.
\end{tabular}

Next, we proceeded with the main analysis that was done in two steps. First, the measurement model was examined. We assessed our measurement model by looking at the loadings, Cronbach's alpha, composite reliability and AVE as suggested in PLS-SEM literature (e.g., Hair et al. 2019). As seen in Table 4 the results of the factor analysis showed satisfactory properties for all constructs. The composite reliability (CR) for all constructs were above the suggested value of 0.6 (Bagozzi and Yi 2012) and the Cronbach alpha was above the recommended level of 0.7, indicating a good internal consistency of the second-order constructs of this study (EDI, structural empowerment and psychological empowerment). Equally, the average variance extracted value (AVE) were satisfactory. All our constructs showed an AVE value that was higher than 0.50 , indicating a sufficient degree of convergent validity. Table 4 shows the standardized factor loading of the reflective constructs, $C R$, Cronbach's alpha and AVE. 
Table 4. Model—standardized factor loadings.

\begin{tabular}{cccc}
\hline & Reflective & Reflective & Reflective \\
\cline { 2 - 4 } & Structural Empowerment & Psychological Empowerment & EDI \\
\hline Opportunity & 0.87 & & \\
Information & 0.87 & & \\
Support & 0.84 & & \\
Resources & 0.77 & 0.79 & \\
\hline Meaning & & 0.54 & \\
Competence & & 0.73 & 0.83 \\
Autonomy & & 0.79 & 0.67 \\
Impact & & & 0.86 \\
\hline Emergence & & & $\mathbf{0 . 7 3}$ \\
Ideagen & & $\mathbf{0 . 7 0}$ & $\mathbf{0 . 6 2}$ \\
Ideaimp & $\mathbf{0 . 8 6}$ & $\mathbf{0 . 8 2}$ & \\
\hline Cronbach & $\mathbf{0 . 9 0}$ & $\mathbf{0 . 5 2}$ & \\
CR(DG) & $\mathbf{0 . 7 0}$ & & \\
AVE & & & \\
\hline
\end{tabular}

Notes: 1. Emergence $=$ emergence and search for ideas, ideagen $=$ idea generation, ideaimp $=$ idea development and implementation; $2 \mathrm{CR}(\mathrm{DG})=$ composite reliability or Dillion-Goldstein's rho, AVE $=$ average variance extracted.

The next step was the evaluation of the structural model. As noted by Venturini and Mehmet (2019), "assessment of the model goodness for a PLS-SEM model is rather complicated and not yet properly defined" (p. 12). To evaluate the quality of our hypothesized model (Figure 1), we reported the path coefficient (standardized) and coefficient of determination $\left(R^{2}\right)$ (Venturini and Mehmet 2019). The $\mathrm{R}^{2}$ for psychological empowerment was 0.53 while that of EDI was 0.50 , indicating a moderate sample's explanatory power.

The results from the PLS-SEM analysis showed support for H1, H2 and H3). Hypothesis 1, which postulated that structural empowerment has a positive relationship with EDI and was supported in a statistically significant way $(\beta=0.48, p<0.001)$. Hypothesis 2 postulated that there is a positive association between structural empowerment and psychological empowerment. This hypothesis was supported $(\beta=0.73, p<0.001)$. Hypotheses 3 , which predicted that there is a positive relationship between psychological empowerment and EDI, was also confirmed $(\beta=0.28, p<0.05)$. Together, structural empowerment and psychological empowerment explained $50 \%$ of the variance in EDI. (shown as Table 5).

Table 5. Model - Standardized path coefficients.

\begin{tabular}{ccc}
\hline Variable & Psychological Empowerment & EDI \\
\hline Structural & $0.73(0.001)$ & $0.48(0.001)$ \\
empowerment & & $0.28(0.05)$ \\
Psychological & $\mathbf{0 . 5 3}$ & $\mathbf{0 . 5 0}$ \\
empowerment & $\mathbf{0 . 5 3}$ & \\
Adjusted $\mathbf{R}^{2}$ &
\end{tabular}

With significant results in all the three parts tested in Hypotheses 1, 2 and 3, preliminary support for $\mathrm{H} 4$ was demonstrated. We tested for mediation by first estimating the indirect effects, and secondly testing the statistical significance (Hair et al. 2019). Accordingly, we found that the mediating effect of psychological empowerment has on the relationship between structural empowerment and EDI was significant $(\beta=0.21, p<0.05)$, thus partial. Thus, we found support for the H4. 


\section{Supplementary Analysis}

To verify if there is any significant difference between study 1 and study 2, we performed a multigroup analysis based on the model depicted in Figure 1. More specifically, we now checked whether the model estimates (path coefficients and loadings) differ between study 1 and study 2 respondents. We did this by merging the two datasets and then performed a multigroup analysis. Here, we used the bootstrap option with 200 replications. We performed this three times, setting a significance level (alpha) of $0.001,0.05$ and 0.10 to check if any part will be significant. The results show the path coefficients for the whole sample (Global) as well as those for study 1 (Group 1) and study 2 (Group 2) samples were insignificant at the three significance levels. All path coefficients were not significantly different between the two organizations. This demonstrates that there is no significant difference between the two studies. See Table 6 and Figure 2 below.

Table 6. Multigroup comparison (organizations)—Bootstrap t-test.

\begin{tabular}{ccccccc}
\hline Structural Effect & Global & Study 1 & Study 2 & Abs Diff & Statistic & $p$-Value \\
\hline Stremp -> Psyemp & 0.742 & 0.743 & 0.732 & 0.011 & 0.249 & 0.804 \\
Stremp -> Edi & 0.386 & 0.375 & 0.483 & 0.107 & 0.858 & 0.391 \\
Psyemp -> Edi| & 0.373 & 0.374 & 0.282 & 0.092 & 0.665 & 0.507 \\
\hline
\end{tabular}

Notes: Number of replications: 200; Group labels: group 1: NAV, group 2: Choice; Group sizes: group 1: 221, group 2: 60 .

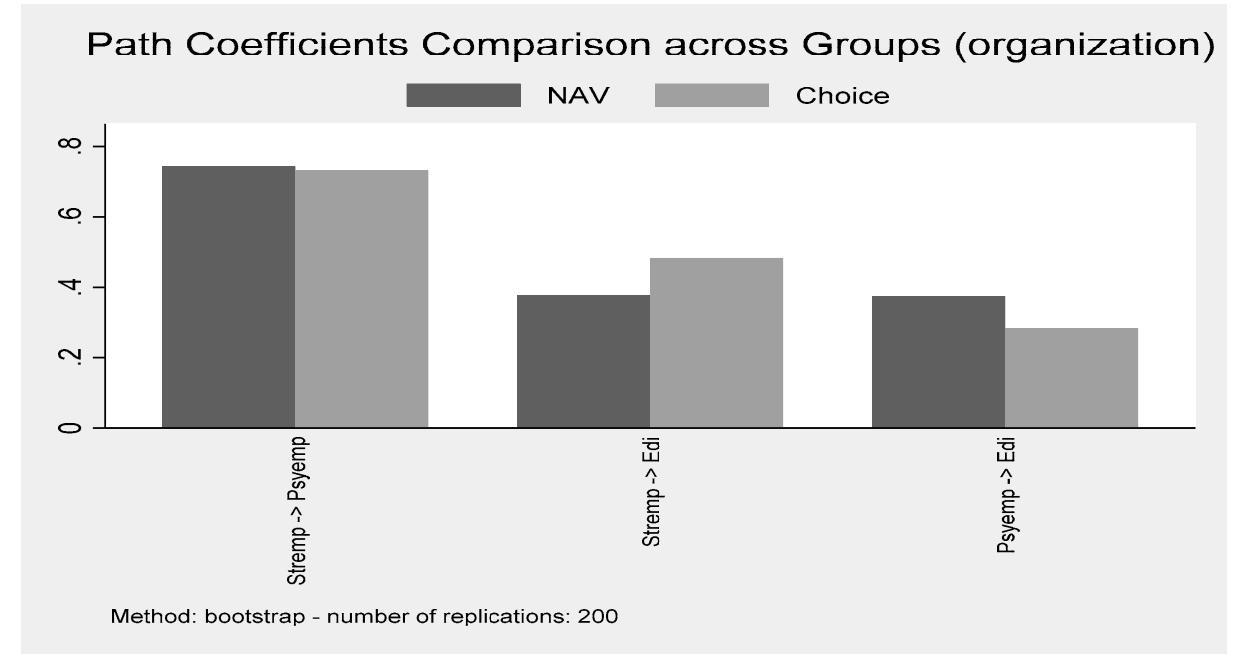

Figure 2. Path coefficients comparison across groups.

\section{Discussion, Implications and Limitations}

The main aim of this study was to empirically test the relationship between the two main approaches of empowerment (structural and psychological empowerment) and EDI, and to determine to what extent psychological empowerment mediates the relationship between structural empowerment and EDI. We tested our hypothesized model in samples drawn from two organizations.

Employee empowerment is a widely studied concept but not empirically linked to EDI. This is particularly important because EDI is about ordinary employees who are not hired for innovation they may need to empowered to engage in innovation activities. This study contributes to the EDI literature by illuminating how empowerment influences ordinary employee participation in innovation.

We found that both structural empowerment and psychological empowerment had a direct positive association with EDI. This finding is theoretically meaningful, since structural empowerment within an organization provides employees with significant opportunities, information, support and resources to take an active role in the innovation process. Likewise, employees feel a state of being psychologically empowered provides them with motivation and initiative to use their creativity and 
effort to generate, develop and implement innovative ideas. These findings indicate that empowerment is a useful and promising concept to enable employees engage in innovation activities. In general, this is consistent with early qualitative studies in which management practices were found to be important for EDI (e.g., Sorensen and Ussing 2018; Voxted 2018; Hansen et al. 2017).

We also found that psychological empowerment partially mediated the relationship between structural empowerment and EDI. The mediation role of psychological empowerment is a well-established mechanism in the literature tasks (Seibert et al. 2011; Amundsen and Martinsen 2015). Previous studies have pointed out that psychological empowerment acts as a mediating mechanism between different independent and dependent variables (Zhang and Bartol 2010; Camilla and Krishna 2015). However, to the best of our knowledge, this is the first study that investigates the construct's mediating role between structural empowerment and EDI. A plausible explanation of our findings is that structural empowerment stimulates psychological motivation processes in employees regarding their work tasks (Amundsen and Martinsen 2015; Rhee et al. 2017), which in turn transmit effects of structural empowerment on EDI.

Furthermore, our study also shows that structural empowerment can also enable EDI directly without going through psychological empowerment as a mediating mechanism. Our finding of a strong relationship between structural empowerment and psychological empowerment was consistent with earlier findings (Laschinger et al. 2001). Additionally, our multigroup analyses indicated that there was no significant difference between the two organizations. That is to say that there were no difference as regard the path coefficient between structural empowerment and EDI and between psychological empowerment and EDI for the two organizations. This suggests that the role of empowerment in facilitating EDI is consistent and that it does not matter whether it occurs in a private or public sector organization.

\subsection{Implications of the Study}

Based on the findings of our study, it is possible to draw out some implications on how organizations can enhance the innovative performance of their regular employees through empowerment. First, for organizations that seek to stimulate and maximize the innovative abilities of ordinary employees, it is crucial to prioritize sources of structural empowerment in the working environment. This implies that regular employees will react positively to the presence of a work environment that provides access to information, access to resources, required support and opportunities. This is the responsibility of managers and management of organizations. Employees on their own cannot provide these empowering structures but instead merely react to their existence. Sometimes these structures are inherent in the organization, whereas during other times, immediate supervisors will have to give employees access to these structures.

Second, managers and the management of organizations need to ensure that structural empowerment initiatives are arranged in such a way that it simultaneously promote a state of feeling psychologically empowered among employees. Psychological empowerment is described as motivational cognitions that can be induced in employees by the organizational environment (Rhee et al. 2017; Conger and Kanungo 1988). It comprises of employees' perceptions of meaning, competence, self-determination and impact in one's work role (Spreitzer 1995). This paper has demonstrated that an employee's state of feeling psychologically empowered has the potential to enable EDI.

\subsection{Limitations of the Study}

The present study has some limitations that are worth mentioning. First, the data for the two studies were based on cross-sectional design. So, causal claims cannot be made. Again, the correlation among the variables could have been inflated by common method bias, even though we employed some ex-ante remedies. We recommend that future studies adopt a cross-lagged approach and separate independent and dependent variables in time. This will help to rule out the possibility of common method variance. Second, the sample size for study two was small compared to for study one. We recommend that 
future studies should be based on larger sample sizes. Third, these studies were conducted in services sectors and in one country. Within the Norwegian context, organizational structures are flattening, and there is less distance between employees and their supervisors. The Norwegian work environment regulations guarantee an employee certain basic structures within their work environment. Without further studies, our research cannot necessarily be generalized to other contexts.

Author Contributions: Conceptualization, C.E., S.A. and M.E; Methodology, C.E. and S.A.; Supervision, S.A. and M.E.; Writing-original draft, C.E., S.A. and M.E. All authors have read and agreed to the published version of the manuscript.

Funding: This research received no external funding

Acknowledgments: The authors wish to thank Ingjerd Thon Hagaseth for her help during the data collection.

Conflicts of Interest: There was no conflict of interest.

\section{References}

Aaltonen, Satu, and Ulla Hytti. 2014. Barriers to Employee-Driven Innovation. The International Journal of Entrepreneurship and Innovation 15: 159-68. [CrossRef]

Aasen, Tone Merethe Berg, Oscar Amundsen, Leif Jarle Gressgård, and Kåre Hansen. 2012. In search of best practices for employee-driven innovation: Experiences from Norwegian work life. In Maria Bonnafous-Boucher, Cathrine Hasse, Maja Lotz and Kirsten Møller. Edited by Steen Høyrup. Basingstoke: Palgrave Macmillan, pp. 57-74.

Acock, Alan C. 2013. Discovering Structural Equation Modeling Using State. College Station: Stata Press.

Alasoini, Tuomo. 2013. Promoting employee-driven innovation: Putting broad-based innovation policy into practice. Paper presented at the Background Paper for the International Helix Conference, Linkoping, Sweden, June 12-14.

Amabile, Teresa M. 1988. A Model of Creativity and Innovation in Organizations. Research in Organizational Behavior 10: 123-67.

Amundsen, Stein. 2014. Empowering Leadership_Leading Employees to Lead Themselves. Ph.D. Dissertation, Norwegian University of Science and Technology, Trondheim, Norway.

Amundsen, Stein. 2019. Empowerment i Arbeidslivet: Et Myndiggjøringsperspektiv på Ledelse, Selvledelse og Medarbeiderskap. Oslo: Cappelen Damm Akademisk.

Amundsen, Stein, and Øyvind L. Martinsen. 2015. Linking Empowering Leadership to Job Satisfaction, Work Effort, and Creativity: The Role of Self-Leadership and Psychological Empowerment. Journal of Leadership $\mathcal{E}$ Organizational Studies 22: 304-23. [CrossRef]

Avolio, Bruce J., David A. Waldman, and Francis J. Yammarino. 1991. Leading in the 1990s: The four I's of transformational leadership. Journal of European Industrial Training 15: 9-16. [CrossRef]

Bäckström, Izabelle, and Lars Bengtsson. 2019. A mapping study of employee innovation: Proposing a research agenda. European Journal of Innovation Management 22: 468-92. [CrossRef]

Båckstrom, Izabelle, and Malin Lindberg. 2018. Behavioral Implications of Employee-Driven Innovation-A Critical Discourse Analysis. International Journal of Innovation Management 22: 1850058. [CrossRef]

Bäckström, Izabelle, and Malin Lindberg. 2019. Varying involvement in digitally enhanced employee-driven innovation. European Journal of Innovation Management 22: 524-40. [CrossRef]

Bagozzi, Richard P., and Youjae Yi. 2012. Specification, evaluation, and interpretation of structural equation models. Journal of the Academy of Marketing Science 40: 8-34. [CrossRef]

Baird, Kevin, Sophia Su, and Rahat Munir. 2018. The relationship between the enabling use of controls, employee empowerment, and performance. Personnel Review 47: 257-74. [CrossRef]

Bos-Nehles, Anna, and Andre A. R. Veenendaal. 2017. Perceptions of HR practices and innovative work behavior: The moderating effect of an innovative climate. The International Journal of Human Resource Management 30: 1-23. [CrossRef]

Buhl, Anke. 2018. Do it yourself-A lean startup toolbox for employee-driven green product innovation. The International Journal of Entrepreneurship and Innovation Management 22: 526-44. [CrossRef] 
Camilla, L. Krog, and Govender Krishna. 2015. The relationship between servant leadership and employee empowerment, commitment, trust and innovative behavior: A project management perspective. South African Journal of Human Resource Management 13: e1-e12. [CrossRef]

Carlborg, Per, Daniel Kindström, and Christian Kowalkowski. 2014. The evolution of service innovation research: A critical review and synthesis. Service Industries Journal 34: 373-98. [CrossRef]

Chang, Sea-Jin, Arjen van Witteloostuijn, and Eden Lorraine. 2010. From the Editors: Common Method Variance in International Business Research. Journal of International Business Studie 41: 178-84. [CrossRef]

Checkbox. 2018. Professional Online Survey Software. Available online: https://www.checkbox.com/ (accessed on 16 April 2020).

Cheong, Minyoung, Seth M. Spain, Francis J. Yammarino, and Seokhwa Yun. 2016. Two faces of empowering leadership: Enabling and burdening. The Leadership Quarterly 27: 602-16. [CrossRef]

Conger, Jay, and Rabindra Kanungo. 1988. The Empowerment Process: Integrating Theory And Practice. Academy of Management. The Academy of Management Review 13: 471. [CrossRef]

Conrad, Lashley. 2017. Employee empowerment in services: A framework for analysis. Personnel Review 28: 169-91.

Conway, James, and Charles Lance. 2010. What Reviewers Should Expect from Authors Regarding Common Method Bias in Organizational Research. Journal of Business and Psychology 25: 325-34. [CrossRef]

Corsun, David L., and Cathy A. Enz. 1999. Predicting Psychological Empowerment Among Service Workers: The Effect of Support-Based Relationships. Human Relations 52: 205-24. [CrossRef]

Dan, Xin, Suhuan Xu, Jingying Liu, Ruonan Hou, Yanhui Liu, and Hongwen Ma. 2018. Relationships among structural empowerment, innovative behavior, self-efficacy, and career success in nursing field in mainland China. International Journal of Nursing Practice 24: 1-9. [CrossRef] [PubMed]

Durst, Susanne, Anne-Laure Mention, and Petro Poutanen. 2015. Service innovation and its impact: What do we know about? Investigaciones Europeas de Dirección y Economía de la Empresa 21: 65-72. [CrossRef]

Echebiri, Chukwuemeka, Marit Engen, and Stein Amundsen. Forthcoming. Employee-Driven Innovation: Conceptualisation, Scale Development and Preliminary Validation. International Journal of Entrepreneurship and Innovation Management.

Fernandez, S., and Tima Moldogaziev. 2013. Using employee empowerment to encourage innovative behavior in the public sector. Journal of Public Administration Research and Theory 23: 155. [CrossRef]

Fernandez, S., and David. W. Pitts. 2011. Understanding employee motivation to innovate: Evidence from front line employees in united states federal agencies. Australian Journal of Public Administration 70: 202-22. [CrossRef]

Hair, Joseph F., G. Tomas M. Hult, Christian Ringle, and Marko Sarstedt. 2019. A Primer on Partial Least Squares Structural Equation Modeling (PLS-SEM). New York: Sage Publications.

Hansen, Kåre, Oscar Amundsen, Tone Merethe Berg Aasen, and Leif Jarle Gressgård. 2017. Management Practices for Promoting Employee-Driven Innovation. In Workplace Innovation: Aligning Perspectives on Health, Safety and Well-Being. Edited by Peter Oeij, Diana Rus and Frank Pot. Berlin: Springer International Publishing, pp. 321-38.

Hartley, Jean. 2005. Innovation in Governance and Public Services: Past and Present. Public Money E Management 25: 27-34. [CrossRef]

Havaei, Farinaz, and V. Susan Dahinten. 2017. How Well Does the CWEQ II Measure Structural Empowerment? Findings from Applying Item Response Theory. Administrative Sciences 7: 15. [CrossRef]

Hebenstreit, J. Julia. 2012. Nurse Educator Perceptions of Structural Empowerment and Innovative Behavior. Nursing Education Perspective 33: 297-301. [CrossRef]

Helkkula, Anu, Christian Kowalkowski, and Bård Tronvoll. 2018. Archetypes of Service Innovation: Implications for Value Cocreation. Journal of Service Research 21: 284-301. [CrossRef]

Holmquist, Mats, and Anna Johansson. 2019. Employee-driven innovation: An intervention using action research. Technology Innovation Management Review 9: 44-53. [CrossRef]

Høyrup, Steen. 2010. Employee-driven innovation and workplace learning: Basic concepts, approaches and themes. Transfer: European Review of Labour and Research 16: 143-54. [CrossRef]

Høyrup, Steen. 2012. Employee-Driven Innovation: A New Phenomenon, Concept and Mode of Innovation. In In Employee-Diven Innovation A new Approach. Edited by Steen Høyrup, Maria Bonnafous-Boucher, Cathrine Hasse, Maja Lotz and Kirsten Møller. New York: Palgrave Macmillian, pp. 3-34. 
Humborstad, Sut I. Wong. 2012. Institutional effects of empowerment: A comparison between the Anglo-Saxon and Scandinavian contexts. The International Journal of Human Resource Management 23: 2221-37. [CrossRef]

Jose, Paul E. 2013. Doing Statistical Mediation \& Moderation. London: Guilford.

Kanter, Rosabeth Moss. 1977. Men and Women of the Corporation, 2nd ed. New York: BasicBooks.

Kanter, Rosabeth Moss. 1979. Power failure in management circuits. Harvard Business Review 57: 65.

Kanter, M. Rosabeth. 1988. When a thousand flowers bloom: Structural, collective, and social conditions for innovation in organization. In Research in Organizational Behavior. Edited by M. Barry Staw and L. L. Cummings. Greenwich: JAI Press, pp. 169-211.

Kesting, Peter, and John Ulhøi. 2010. Employee-driven innovation: Extending the license to foster innovation. Management Decision 48: 65-84. [CrossRef]

Kesting, Peter, Lynda Jiwen Song, Zhihua Qin, and Michal Krol. 2015. The role of employee participation in generating and commercialising innovations: Insights from Chinese high-tech firms. The International Journal of Human Resource Management 27: 1059-81. [CrossRef]

Knol, Jeannette, and Roland Van Linge. 2009. Innovative behavior: The effect of structural and psychological empowerment on nurses. Journal of Advanced Nursing 65: 359-70. [CrossRef] [PubMed]

Kurz, Veronika, Stefan Husig, and Michael Dowling. 2018. What drives different employee types of innovative behavior? Development and test of an integrative model of employee-driven innovation in German firms. The International Journal of Entrepreneurship and Innovation Management 22: 397-426. [CrossRef]

Laschinger, Heather K., Joan Finegan, Judith Shamian, and Piotr Wilk. 2001. Impact of Structural and Psychological Empowerment on Job Strain in Nursing Work Settings. JONA 31: 260-72. [CrossRef]

Laschinger, Heather K., Joan Finegan, Judith Shamian, and Piotr Wilk. 2004. A longitudinal analysis of the impact of workplace empowerment. Journal of Organizational Behavior 25: 527-45. [CrossRef]

Lempiala, Tea, and Sari Yli-Kauhaluoma. 2019. Similar structures, different interpretations: Perceived possibilities for employee-driven innovation in two teams within an industrial organisation. The International Journal of Entrepreneurship and Innovation Management 22: 362-80. [CrossRef]

Maynard, M. Travis, Lucy L. Gilson, and John E. Mathieu. 2012. Empowerment-Fad or Fab? A Multilevel Review of the Past Two Decades of Research. Journal of Management 38: 1231-81. [CrossRef]

Mehmet, Mehmetoglu, and Tor Georg Jakobsen. 2017. Applied Statistics Using Stata: A Guide for the Social Sciences. London: SAGE.

Menon, Sanjay. 2001. Employee Empowerment: An Integrative Psychological Approach. Applied Psychology 50: 153-80. [CrossRef]

O’Brien, Anice L. 2010. Structural Empowerment, Psychological Empowerment and Burnout in Registered Staff Nurses Working in Outpatient Dialysis Center. Ph.D. Thesis, The State University of New Jersey, New Brunswick, NJ, USA.

Osborne, Stephen P., and Louise Brown. 2011. Innovation, Public Policy and Public Services Delivery in the UK. The Word That Would Be King? Public Administration 89: 1335-50. [CrossRef]

Pieterse, Anne Nederveen, Daan van Knippenberg, Michaéla Schippers, and Daan Stam. 2010. Transformational and transactional leadership and innovative behavior: The moderating role of psychological empowerment. Journal of Organizational Behavior 31: 609-23. [CrossRef]

Podsakoff, Philip M., Scott B. MacKenzie, Jeong-Yeon Lee, and Nathan P. Podsakoff. 2003. Common method biases in behavioral research: A critical review of the literature and recommended remedies. Journal of Applied Psychology 88: 879-903. [CrossRef] [PubMed]

Renkema, Maarten. 2018. Innovating HRM for Employee-Driven Innovation: A Multilevel Perspective. Ph.D. Thesis, University of Twente, Enschede, The Netherlands.

Renkema, Maarten, Jeroen Meijerink, and Tanya Bondarouk. 2018. Routes of Employee-Driven Innovation: How HRM Supports Emergence. Academy of Management Proceedings 2018: 16237. [CrossRef]

Rhee, Jaehoon, Seo Dae Seog, Faridun Bozorov, and Alisher Tohirovich Dedahanov. 2017. Organizational structure and employees' innovative behavior: The mediating role of empowerment. Social Behavior and Personality: An International Journal 45: 1523. [CrossRef]

Russell, Robert F., and A. Gregory Stone. 2002. A review of servant leadership attributes: Developing a practical model. Leadership \& Organization Development Journal 23: 145-57.

Saari, Eveliina, Mikko Lehtonen, and Marja Toivonen. 2015. Making bottom-up and top-down processes meet in public innovation. The Service Industries Journal 35: 325-44. [CrossRef] 
Seibert, Scott E., Gang Wang, and Stephen H. Courtright. 2011. Supplemental Material for Antecedents and Consequences of Psychological and Team Empowerment in Organizations: A Meta-Analytic Review. Journal of Applied Psychology 96: 981-1003. [CrossRef]

Smith, Pernille, John Ulhøi, and Peter Kesting. 2012. Mapping key antecedents of employee-driven innovations. International Journal of Human Resources Development and Management 12: 124-236. [CrossRef]

Snyder, Hannah, Lars Witell, Anders Gustafsson, Paul Fombelle, and Per Kristensson. 2016. Identifying categories of service innovation: A review and synthesis of the literature. Journal of Business Research 69: 2401-8. [CrossRef]

Sorensen, Henrik, and Lene Faber Ussing. 2018. Key mechanisms for employee-driven innovation in governmental client organisations. International Journal of Entrepreneurship and Innovation Management 22: 427-50. [CrossRef]

Spreitzer, Gretchen M. 1995. Psychological Empowerment in the Workplace: Dimensions, Measurements, and Validation. Academy of Management 38: 1442-65.

Spreitzer, G., and David Doneson. 2005. Musings on the Past and Future of Employee Empowerment. In Handbook of Organizational Development. Edited by Tom Cummings. Thousand Oaks: Sage.

Spreitzer, Gretchen M., Suzanne C. De Janasz, and Robert E. Quinn. 1999. Empowered to lead: The role of psychological empowerment in leadership. Journal of Organizational Behavior 20: 511-26. [CrossRef]

StataCorp. 2017. Stata Statistical Software: Release 15. College Station: StataCorp. LLC.

Thomas, Kenneth W., and Betty A. Velthouse. 1990. Cognitive Elements of Empowerment: An Interpretive Model of Intrinsic Task Motivation. The Academy of Management Review 15: 666-81.

Thorlakson, Alan JH, and Robert P. Murray. 1996. An empirical study of empowerment in the workplace. Group $\mathcal{E}$ Organization Management 21: 67-83.

Totterdill, Peter, and Rosemary Exton. 2014. Defining workplace innovation. Strategic Direction 30: 12-16. [CrossRef]

Vecchio, Robert P., Joseph E. Justin, and Craig L. Pearce. 2010. Empowering leadership: An examination of mediating mechanisms within a hierarchical structure. The Leadership Quarterly 21: 530-42. [CrossRef]

Venturini, Sergio, and Mehmetoglu Mehmet. 2019. plssem: A Stata Package for Structural Equation Modeling with Partial Least Square. Journal of Statistical Software 88: 1-35. [CrossRef]

Voxted, Søren. 2018. Conditions of implementation of employee-driven innovation. International Journal of Entrepreneurship and Innovation Management 22: 471-88. [CrossRef]

Wagner, Joan I. J., Greta Cummings, Donna L. Smith, Joanne Olson, Lynn Anderson, and Sharon Warren. 2010. The relationship between structural empowerment and psychological empowerment for nurses: A systematic review. Journal of Nursing Management 18: 448-62. [CrossRef] [PubMed]

Wang, Xiao-Hua, Yulin Fang, Israr Qureshi, and Onne Janssen. 2015. Understanding employee innovative behavior: Integrating the social network and leader-member exchange perspectives. Journal of Organizational Behavior 36: 403-20. [CrossRef]

Wihlman, Thomas, Magnus Hoppe, Ulla Wihlman, and Helene Sandmark. 2014. Employee-driven Innovation in Welfare Services. Nordic Journal of Working Life Studies 4: 159-80. [CrossRef]

Witell, Lars, Hannah Snyder, Anders Gustafsson, Paul Fombelle, and Per Kristensson. 2016. Defining service innovation: A review and synthesis. Journal of Business Research 69: 2863-72. [CrossRef]

Wong, Ken Kwong-Kay. 2019. Mastering Partial Least Squares Structural Equation Modeling (PLS-SEM) with SmartPLS in 38 Hours. Bloomington: iUniverse.

Wong Humborstad, Sut I., and Chad Perry. 2011. Employee empowerment, job satisfaction and organizational commitment. Chinese Management Studies 5: 325-44. [CrossRef]

Zhang, Xiaomeng, and Kathryn Bartol. 2010. Linking Empowering Leadership and Employee Creativity: The influence of Psychological Empowerment, Intrinsic Motivation, And Creativity Process Engagemenet. Academy of Management Journal 53: 107-28. [CrossRef]

(C) 2020 by the authors. Licensee MDPI, Basel, Switzerland. This article is an open access article distributed under the terms and conditions of the Creative Commons Attribution (CC BY) license (http://creativecommons.org/licenses/by/4.0/). 